\title{
AN ANALYSIS OF MANAGING THE QUALITY AND ACCESSIBILITY OF HIGHER EDUCATION THROUGH THE USE OF ICT IN A DEVELOPING COUNTRY - BLENDED LEARNING MODEL
}

\author{
Mrs. J. Thevananth \\ University of Jaffna, Jaffna, Sri Lanka \\ Email: jananithevananth@yahoo.co.in
}

\begin{abstract}
Technology has a new trend in this globalization century. It changes the education at all levels, especially in higher education (HE), enhancement of ICT augmentation the quality of learning and teaching. Using ICT in education developed after 2005, in developing countries. Nowadays, higher education institutions are practicing their course delivering methods using learning management system and traditional face to face methods. The blended learning (BL) approach delivers an efficient and effective environment in higher education. However, implementing the BL has its challenges to the HE in all levels of pedagogical and lack of knowledge regarding the use of technology.

This research focused on how to combine technology and education, how it would stimulate learning and teaching and how to make it to get more effective products. The researcher proposed that higher education adopt a Demarcated Learning Management System (LMS) Defined Implementation Model - Evaluation, Implementation, Determination, and Analysis Process (EIDA) - to establish a well-defined methodology for finding BL Model to support higher education teaching and learning.

This study found that EIDA process would make higher education, in the use of blended learning, maintain their pedagogical quality and accessibility. It leads to blended Learning which is considered the best learning model without losing the benefits of the traditional face-to-face learning and considered the drawback of the excluding use of information communication technology.
\end{abstract}

Keywords: Blended Learning, Information and Communication Technology, Pedagogy.

\section{Introduction}

Sri Lanka is a country in the developing world with a high level of literacy and a wellestablished policy of free education. During the two last decades the country's use of Information and Communication Technology (ICT) has increased. The history of ICT and Blended Learning in Sri Lanka is relatively young phenomenon. Academic institutions in Sri Lanka are changing quality improvements for their teaching and learning and are, therefore, subjected to change their processes with the aid of Information Technology.

In our higher education teaching method, blended learning activities are common with many courses. It is designed as a combination of face to face traditional activities, such as attending to lectures, participation in tutorials or practical works in the lab and sitting to paper based end semester examination, and e-Learning activities, such as online quizzes, wiki, blogs and use different forums via LMS. The value of higher education is to hold the promise of opportunity for improvements in the quality of life for people of all cultures (Chew, 2009; Moller, 2004; Watson, 2001). They also said "Technology breakthroughs have 
held the promise to improve life. ICT is often seen as a "Catalyst for change" that impact on teaching style and learning approaches".

Allens (2007) current research supported that the use of blended learning model is complex and varied, as well as reflects a dynamic state of flux in higher education. In higher education, there are challenges to face the lack of knowledge to use the technology and pedagogy to adopt this blended learning model.

\section{Research Problem}

Higher education institutions in Sri Lanka endorse the use of BL in their teaching and learning, since it delivers a more time effective and pedagogically supportive model with information and communication technology. Graham \& Gibbons (2014), supported that, well-established scholarly domain have common terminology and widely accepted models and theories that guide inquiry and practice, while researchers in less mature domains struggle to define terms and establish relevant models. The higher education must be coherent to a pedagogically sound and use of ICT in their environment. In practice, thereis a lack of frame work to model blended learning for all disciplines of pedagogies for teaching and learning.

In the higher education, the students in blended learning programmes assumed that, fewer classes meant less work, inadequate time management skills were inadequate, and they experienced problems with accepting responsibility for personal learning (Vaughan, 2007). A solution is needed to find a Demarcated Learning Management System (LMS) to establish a well-defined methodology for finding BL Model to support higher education teaching and learning.

\section{Research Questions}

There are three main research questions.

1. What are the main challenges in higher education institutions when they are practicing the BL courses?

2. What are the satisfaction levels of participants in a blended learning environment?

3. How a Demarcated Learning Management System can reinforced the HE institutions to implement the BL courses.

\section{Literature Review}

\subsection{Blended learning}

There are many definitions found related with Blended Learning. This study subscribes to Bonk and Graham (2006) defined that, Combining instructional modalities or delivery media and technologies (traditional distance education, Internet, Web, CD ROM, video/audio, or any other electronic medium, email, online books etc.) and combining instructional modalities, learning theories and pedagogical dimensions also combining elearning with face-to-face learning.

Littlejohn and Pegler (2007) provide their ideas into dimensions of four general areas as follows: The space blend: faf or technology mediated communication; the time blend: geographically and availability; synchronously or asynchronously; the media blend: tools, technologies and resources; the activity blend: learning and teaching activities, individual or group.

These definitions and dimensions furnish a general background and setting of blended learning. They recommend that three factors must be taken into account in the setting of blended learning: (1) the purpose of the learning, (2) the context of the learning and (3) the approach to teaching and learning. This research considered Littlejohn's process because the researcher has experiences to find the model of the blended learning is an intricate process which requires neither absolute definition nor fixed phenomena. Because education is the 
complex process, depends on the learning and their environments, the definition may change differently.

In this research, the researcher intended to extend Bonk and Grahams' $1^{\text {st }}$ and $3^{\text {rd }}$ definitions were the working definition of this work.

\subsection{Existing e-learning frameworks}

Khan's eight-dimensional e-learning frameworks shown in figure 1 bring together the design, delivery, implementation, and evaluation of e-learning. It considered pedagogical, technological, interface design, evaluation, management, resource support, ethical and institutional. Khan's Octagonal Blended Learning Model Pedagogical dimension concerned itself with the combination and selection of the learning contents to be delivered online and to be delivered offline (face-to-face). It also analyses the learners' learning style, objective of the contents, and evaluates students learning outcomes. This frame work helps as a guide to develop, deliver, manage and evaluate BL programs (Singh, 2003). Also suggested, this frame work guide in many different ways to the institutional development.

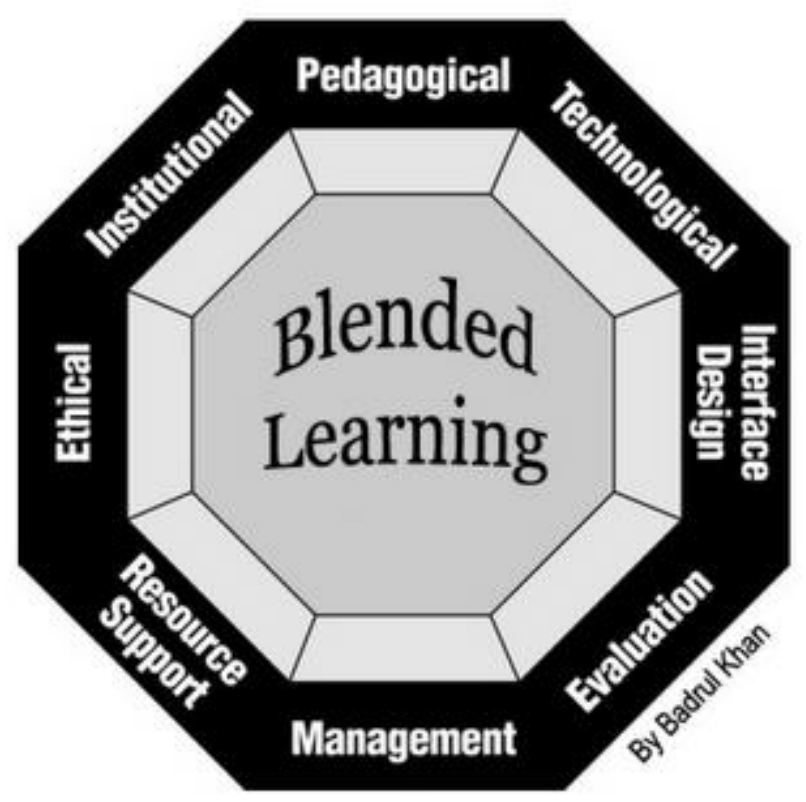

Figure 1: Khan's Octagonal Framework

The framework for systematic learning management system process Improvement Model was developed by Ashraf (2011). It consists of the elements of Opening, Analyzing, Stimulation, and Achieving Processes (OASA) -to establish a well-designed, effective faculty development program for BL teaching and learning. This approach helped the educational institutions overcome challenges related to faculty's lack of knowledge in using technology in teaching.

Another model for Adoption of Online learning (FAOL) was developed by Faridha (2005), consist of elements Access, Cost, Technologies, Interactivity, Organization, Novelty and speed. This model gathered the learning issues under education, Management and student ownership and readiness.

There are different models: Frame work for success (Jennifer, 2005), Leadership, Academic and Student Ownership and readiness (LASO),Demand-driven Learning Model (MacDonald et al, 2001) analyzed in this research. Khan's Octagonal frame work and Ashraf (OASA) were considered in this development of researcher model, it covered more dimensions of elements in the process of EIDA. 


\section{Research Design}

In this research process, improvement is seen as a way to conceptualize a solution to the research problem. Khan's octagonal framework was used as a grounded theory for the research to establish different views of phenomena and conducted to review resources and tools of e-learning programs. Open-ended interviews, literature review and qualitative data collection based on prototype of the conceptual solution were used to evaluate the demonstration of the concept. Ashraf (2011) used as the systematic approach combined with design-based approach to find the OASA model. As a combination of these the researcher used the following process shown in figure 2, to define an EIDA Model.

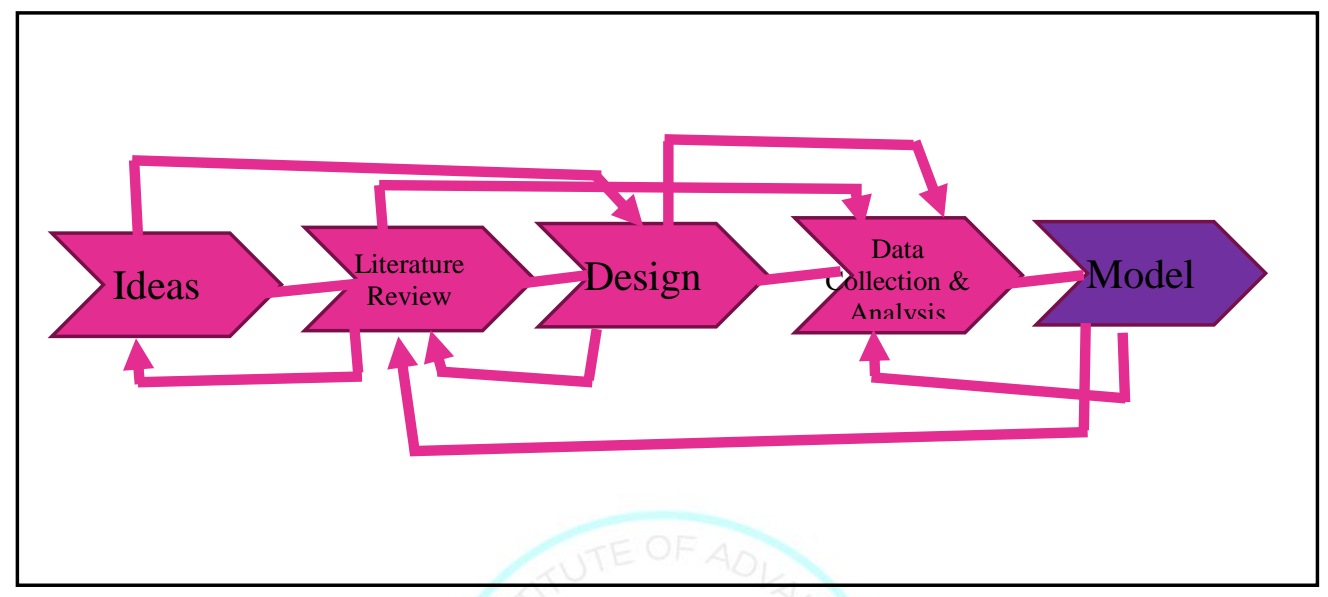

Figure 2: Qualitative Design-based Approach

The key elements of this research approach encompassed qualitative analysis, grounded theories; Khan Octagonal frame work, OASA Process Model, demonstrating the conceptual solution, prototype evaluation and research validation. Research method included literature, past experiences, observations, focus group discussions, data collection from proto type evalution, validation of demonstration of concept.

EIDA - Model

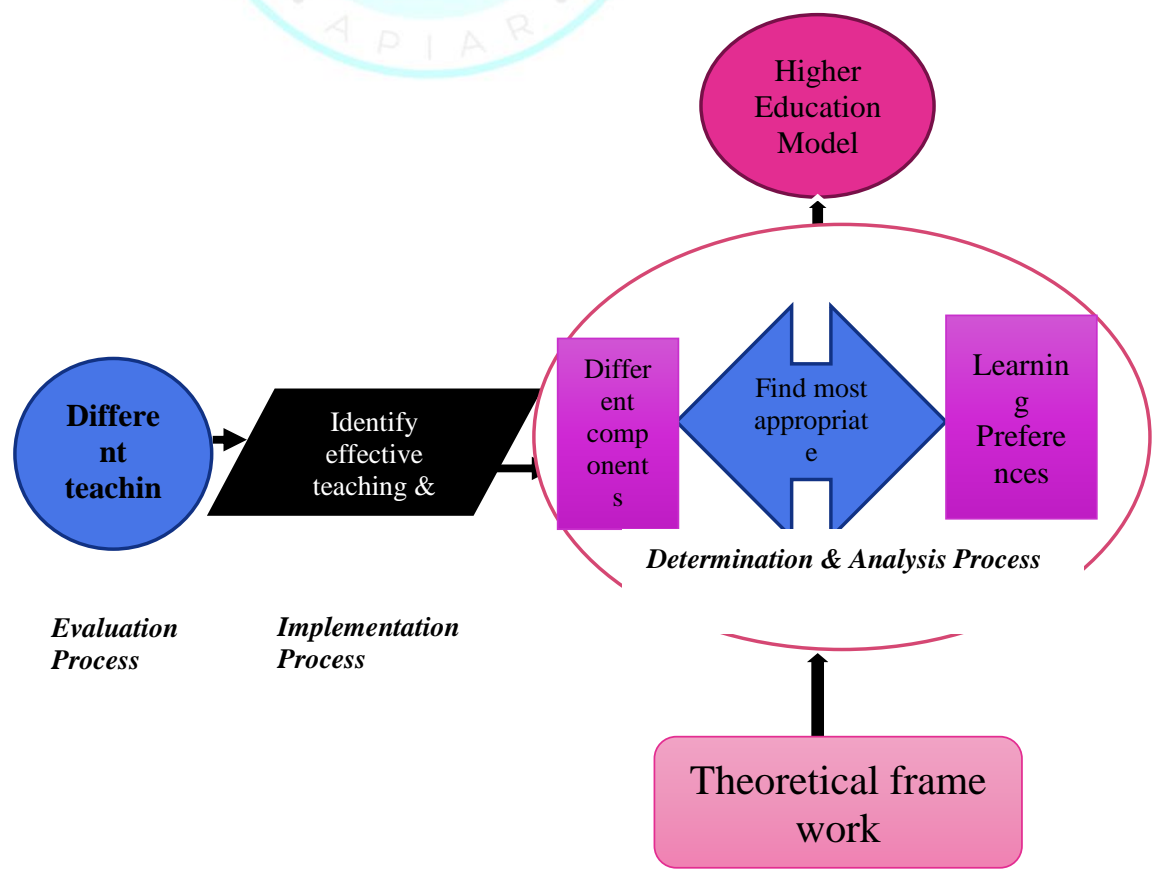

Figure 3:The process of the EIDA model of the demarcated Learning Management System 


\section{Conclusion}

EIDA was established by the prototypes verified by the conceptual solutions.

The higher education face many challenges when practicing the blended learning courses such as lack of knowledge of using information technology, designing courses, using skills, pedagogical implementation and inconsistent software challenges. The main challenge is using the portion of the blended learning components in an appropriate way to support their pedagogical implementation.

Practicing BL courses have very low level of satisfaction in both teacher and student level. The research proposed a model, Demarcated Learning Management System to establish a well-designed and effective blended learning teaching and learning model. This model was defined in a process of Evaluation, Implementation Determination and Analysis. It expands the knowledge regarding BL, enhancing understanding about pedagogies, and increases the satisfaction level of using BL in Higher Education.

EIDA model practiced generally in the process, but was not considered by different subjects and practical issues. Future research could cover these aspects. 


\section{References}

i. Akpan, Ekemini. (2015). Blended learning opportunities and challenges in Mathematics Education: perspective in higher education. South American journal of academic research 2.

ii. Allen,I.,E., Seaman,J. and Garrett,R. (2007). Blended In: The Extent and Promise of Blended Education in the United States. Needham,MA: Sloan-Consortium.

iii. Ashraf,M.B.,(2011). A Systematic Approach to Faculty Development Toward Improved Capability in Tertiary Teaching in a Blended Learning Environment. A Research Dissertation Submitted to the Graduate School in Partial Fulfillment of the Requirments for the Award of the Degree of Doctor of Management in Information Technology, Lawrence Technology University.

iv. Bonk, C.J., \& Graham, C.R. (2006). The handbook of blended learning environments: Global perspectives, local designs. San Francisco: Jossey-Bass/Pfeiffer

v. Chew,E. and Jones,N. (2009). Driver or Drifter? Two case studies of the Blended Learning Practices in Higher Education, In Wang,F.,L.,Fong,J. and Kwan,R. (Eds) The handbook for Hybride learning . PA: Information Science references.

vi. Fardha,M.(2005). Towards Enhancing Learning with Information and Communication Technology in Universities; A Framework for Adaptation of Online Learning. A Research Dissertation Submitted to the Graduate School in Partial Fulfilment of the Requirements for the Award of the Degree of Master of Science in Computer Science of Makerere University, Kampala-Uganda.

vii. Graham,C.R.,Henrie,C.R.,\&Gibbons.A.S.(2014) Developing models and theory for blended learning research. In Picciano,A.,Dziuban,C.D., \&Graham,C.R.(eds) Blended Learning perspectives,vol 2.2(pp13-33).Newyork:Routledge/Taylor Francis Group.

viii. Khan, B. A.,(2003) framework for E-learning.

ix. Littlejohn,A. and Pegler,C. (2007) Prepared for Blended E-Learning, London, Routledge.

x. MacDonald,E.,(2001). The demand-driven learning model: A framework for Web-based learning,The Internet and Higher Education, vol 4,Iss 1,1 ${ }^{\text {st }}$ quarter, pp. 9-30

xi. Moller, L.(2004). Conference keynotes for Educational Communication and Technology conference on Emerging technologies and theories for Teaching and Learning,SpringerLink: Journal of Tech Trends, 48(4), 14-15.

xii. Singh H.,(2003). Building effective learning programs. Educational technology.43:51-54.

xiii. Vaughan, N. (2007). Perspectives on blended learning in higher education. International Journal on eLearning, 6(1), pp. 81-94.

xiv. Watson,D.(2001). Pedagogy before Technology: Re-thinking the Relationship Between ICT and Teaching, Education and Information Technologies, 6(4), pp.251-266. 